\title{
O CONDOMÍNIO EDILÍCIO E SUAS PECULIARIDADES
}

Israel Matheus Cardozo Silva Coutini, Thais Fernanda Silva Rogerio, Pedro Teófilo de Sá

Universidade do Oeste Paulista - UNOESTE, curso de Direito, Presidente Prudente, SP. E-mail:

israelmatheus2010@hotmail.com

\section{RESUMO}

Este trabalho tratou do condomínio edilício e suas importâncias. Assim, o objetivo deste estudo foi demonstrar, ao leitor, o que é o condomínio edilício e a importância de se conhecer desta vertente do direito de propriedade, bem como interpretações doutrinárias e jurisprudenciais acerca das normas que o rege. A metodologia constou de várias obras dos mais populares autores brasileiros da área do Direito Civil. Os resultados foram convincentes e foi possível observar que o condomínio edilício ainda perdura e tende a aumentar. Conclui-se, o condomínio edilício é uma importante aba do direito material, muito comum desde os tempos mais antigos, que está ligado intimamente ao direito constitucional, como qualquer ramo do direito, fazendo-se disto sua importância para o presente estudo.

Palavras-chave: Condomínio Edilício, Noções Gerais, Direitos e Deveres, Permissão de Animais, Obras e Benfeitorias.

\section{THE CONDOMINIUM BUILDING AND ITS PECULIARITIES}

\section{ABSTRACT}

This work dealt with the condominium building and its importance. Thus, the objective of this study was to demonstrate to the reader what is the condominium building and the importance of knowing this aspect of property law, as well as doctrinal and jurisprudential interpretations about the rules that govern it. The methodology consisted of several works by the most popular Brazilian authors in the area of Civil Law. The results were convincing and it was possible to observe that the condominium building still lasts and tends to increase. In conclusion, the building condominium is an important flap of material law, very common since the earliest times, which is closely linked to constitutional law, as any branch of law, making this its importance for the present study.

Keywords: Building Condominium, General, Rights and Duties, Pet Permission, Works and Improvements.

\section{INTRODUÇÃO}

Antigamente, com a ida do homem do campo para as zonas urbanas, a sociedade obrigatoriamente passou por grandes mudanças e aperfeiçoamentos. A massa da população aumentou gradualmente com o êxodo rural, resultando em uma escassez de moradia, dada a ausência de espaços para construções, além da baixa capacidade financeira dos novos integrantes das zonas urbanas.

A melhor solução encontrada para dita situação, então, foram as construções edilícias, conjunto de residências, como se um único imóvel fossem, ocupando pouco espaço, além de razoável custo-benefício, atendendo-se às necessidades da época.

Atualmente, os condomínios edilícios estão presentes em quase todas as cidades do mundo - em especial as brasileiras -, sendo em algumas delas a maioria das moradias. 
Para o melhor entendimento, em primeiro plano, serão apresentadas as noções gerais do condomínio edilício, além de sua historicidade. Num outro momento, serão abordadas as principais características e, enfim, pontos mais influentes do Direito Condominial.

\section{ASPECTOS GERAIS DO CONDOMÍNIO EDILÍCIO}

A noção de condomínio edilício existe desde a Roma Antiga, época em que se passou ao desenvolvimento de estruturas mais sofisticadas de moradia. (VENOSA, 2013)

Entretanto esta noção começou a ganhar força a partir do século XVIII e teve seu auge no século XX, sobretudo com o êxodo rural. Tal fenômeno desencadeou uma espécie de crise de moradia, já que os espaços para construção se encontravam cada vez mais escassos, dada a superpopulação das cidades ${ }^{1}$. Diante disto, a solução mais apropriada foi a criação de edifícios, para que se aproveitasse o máximo do espaço das áreas disponíveis, atendendo-se às demandas da época, ganhando força até hoje, em quase todas as cidades do mundo.

Logo, condomínio ${ }^{2}$ nada mais é que a propriedade em comunhão com dois ou mais sujeitos, denominados condôminos, significando dizer que ambos são simultaneamente donos do todo de determinada coisa.

O direito brasileiro não disciplinava o condomínio no Código Civil de 1916, pois tal situação ganhou peso quando o diploma já se encontrava posto no ordenamento. Assim, cogitou-se em criar uma legislação própria, resultando-se na sucessiva criação de vários diplomas, tais como o Decreto-Lei n. 5.481, de 25 de junho de 1928, Decreto-Lei n. 5.234, de 8 de fevereiro de 1943, e Lei n. 285, de 5 de junho de 1948, até chegar a Lei n. 4.591, de 16 de dezembro de 1964, que, no ano seguinte, sofreu alterações pela Lei n. 4.864, de 29 de novembro de 1965.

Naquela época - a partir da segunda metade do século - já estava em andamento o projeto de um novo Código Civil, que só fora aprovado décadas depois, entrando em vigor apenas em 2002. Tal diploma é de suma importância, pois passou a disciplinar, de forma mais específica e detalhada que a supra referida lei, o condomínio edilício (art. 1.331 a 1.358 do CC), mas com referência à aplicação daquela. Assim, importante é o esclarecimento de Gonçalves (2016, p. 357):

O Código Civil de 2002, apesar de expressa remissão à lei especial, que continua em vigor, contém dispositivos regrando os direitos e deveres dos condôminos, bem como a competência das assembleias e dos síndicos. Nesses assuntos, a referida Lei n. 4.591, de 1964, aplica-se apenas subsidiariamente.

Portanto, pacificamente entende-se, o Código Civil de 2002 revogou, tacitamente, a primeira parte da tal lei (por força do teor do art. 2.ㅇ, § 1.으, da LINDB), já que o mesmo não faz menção no art. $2.045 .^{3}$

\section{INSTITUIÇÃO}

Para se instituir o condomínio edilício necessária é a observância do art. 1.332 do CC, por ato inter vivos ou mortis causa. Os documentos que se destinam à sua criação devem conter:

a) "a discriminação e individualização das unidades de propriedade exclusiva, estremadas uma das outras e das partes comuns": significa dizer que deverá constar no instrumento todas as medidas e demais especificações das áreas de uso comum, bem como as autônomas;

\footnotetext{
${ }^{1}$ Essa modalidade especial de condomínio surgiu depois da guerra de 1914-1918, em consequência da crise de habitações [...] (BARROS MONTEIRO, W. de; DABUS MALUF, C. A., 2013, p. 289).

${ }^{2} \mathrm{O}$ termo "condomínio" originou-se do latim condominium, (copropriedade), composto por com (junto), mais dominium, (poder sobre), que é derivado de dominus (senhor) e domus (casa).

${ }^{3}$ MONTEIRO, W. de B.; DABUS MALUF, C. A. Curso de Direito Civil: direito das coisas. v. 3. 43. ed. São Paulo: Saraiva, 2013 , p. 299.
} 
b) "a determinação da fração ideal atribuída a cada unidade, relativamente ao terreno e partes comuns": a fração ideal refere-se ao quinhão ou cota que cada condômino exercerá seu direito no imóvel - é necessário atentar, as áreas de uso comum, via de regra, não podem ser limitadas ao uso de qualquer dos condôminos;

c) "o fim a que as unidades se destinam": no documento deverá estar expressa qual a finalidade que cada área terá, isto é, qual o uso indicado.

Após, serão formados dois indispensáveis instrumentos para o condomínio, quais sejam, a Convenção e o Regimento Interno. Na Convenção constarão direitos e deveres dos condôminos detalhados adiante. Trata-se de espécie de estatuto, aprovado por pelo menos dois terços das frações ideais ${ }^{4}$.

O Regimento Interno é definido por Rodrigues (2009, p. 218) da seguinte forma: "Sua finalidade é meramente interna, trazendo normas minuciosas sobre o uso das coisas comuns. Em geral, podem ser lidos em tabuletas, colocadas ao lado dos elevadores, no andar térreo."

Em suma, para validação da instituição, a mesma deverá ser registrada no Cartório de Registro de Imóveis do local onde situar o imóvel. ${ }^{5}$

\section{COMPOSIÇÃO}

O condomínio edilício é composto por unidades autônomas e também áreas comuns. As unidades autônomas referem-se às áreas limitadas ao uso particular de cada condômino. Vale dizer, o local em que ele se alimenta, repousa, faz suas necessidades etc. Estas podem ser gravadas pelo seu proprietário quando bem entender, salvo nos casos de garagens no imóvel, que será necessária autorização (art. 1. 338 do CC).

Nas áreas comuns, estes direitos são vislumbrados amplamente, pois o condômino divide o usufruto destas com os demais; seu direito está limitado ao direito dos outros condôminos.

\section{DIREITOS DOS CONDÔMINOS}

Os direitos dos condôminos são os mesmos da propriedade, quais sejam, usar, gozar e dispor da coisa (1.228 do CC) - estes são tidos como os principais direitos. No Código Civil, o legislador trata de tais direitos no art. 1.335 e seus incisos, que serão analisados adiante:

I - usar, fruir e livremente dispor das suas unidades - como salientado supra, são os atinentes ao direito de propriedade. ${ }^{6}$

II - usar das partes comuns, conforme a sua destinação, e contanto que não exclua a utilização dos demais compossuidores - não pode o condômino desviar a função ou finalidade das partes comuns, como fins comerciais, bem como tolher o direito de uso dos demais condôminos.

III - votar nas deliberações da assembleia e delas participar, estando quite - trata-se da democracia exigida no condomínio, podendo o poder de voto corresponder à fração ideal.

O rol do art. 1.335 do CC não é taxativo (numerus clausus), sendo livres outras deliberações. Uma delas é a permissibilidade de animais no condomínio. O tema já causou grandes polêmicas, tanto na jurisprudência quanto na doutrina. Diante disto, o Superior Tribunal de Justiça teve de pacificar a situação, mantendo uma decisão do Tribunal a quo, do Distrito Federal:

\footnotetext{
${ }^{4}$ O Código Civil não especifica os requisitos para se formar a Convenção. Assim, segue-se o art. 9.o da Lei n. 4.591/64, não obstante o art. 1.333 daquele diploma. (RODRIGUES, 2009)

${ }^{5}$ Portanto, há que se entender que a instituição do condomínio, que se aperfeiçoa pelo registro na Circunscrição Imobiliária (Lei n. 6.015, de 31-121973, art. 167, I, n. 17), só se admite após aprovação da Convenção e do Regulamento (RODRIGUES, Silvio, 2009, p. 210).

${ }^{6}$ O primordial direito do adquirente da unidade é o de usar, gozar e dispor dela, com exclusão de qualquer outra pessoa, independentemente do consentimento dos proprietários de outras unidades (MONTEIRO, W. de B.; DABUS MALUF, C. A., 2013, p. 305).
} 
[...] AÇÃO DE OBRIGAÇÃO DE NÃO FAZER. CONDOMÍNIO VERTICAL. ANIMAL DE PEQUENO PORTE. TOLERÂNCIA. 1. Embora remanesça na jurisprudência alguma divergência a respeito da proibição de animais em apartamentos em condomínios verticais, a questão tem sido flexibilizada, sobretudo quanto aos animais de pequeno porte que não tragam transtornos aos demais-condôminos e perturbem o sossego alheio. A presença de cachorro de pequeno porte no interior da unidade autônoma de propriedade da condômina não traz inconveniente que justifique a admissibilidade do animal na área privativa do edifício. 2. Por outro lado, as normas que restringem $o$ trânsito de animais pelas áreas comuns do condômino, Como o elevador de serviço, bem como que determinam o uso de focinheiras, são justificáveis, pois estão em consonância com a finalidade das regras condominiais, que é a proteção do sossego, segurança e saúde dos moradores [...] $]^{7}$ (sic)

Assim, é possível concluir, o direito de propriedade (art. 5으, XXII, da CF) prevalece sobre as convenções condominiais que proíbem animais em suas permanências, sendo necessário, tãosomente, atenção ao porte e periculosidade do semovente, eis que não deve causar incômodos. ${ }^{8}$

\section{DEVERES DOS CONDÔMINOS}

Diferentemente dos direitos, os deveres dos condôminos são numerus clausu, isto é, taxativos. Estão previstos no art. 1.336 do CC e serão ponderados apenas os seus incisos, abaixo.

I - contribuir para as despesas do condomínio na proporção das suas frações ideais, salvo disposição em contrário na convenção - "É um ônus real, que deve ser suportado por quem tiver a coisa no seu domínio; trata-se, pois, de uma obrigação propter rem (em virtude da coisa).." ${ }^{9}$

II - não realizar obras que comprometam a segurança da edificação - é obrigação negativa que proíbe o condômino de mexer na estrutura da coisa, visto o risco que pode acarretar.

III - não alterar a forma e a cor da fachada, das partes e esquadrias externas - também obrigação negativa, na qual não se pode promover mudanças na arquitetura do prédio, já que esta iniciativa parte de um sujeito e não da coletividade condominial.

$I V$ - dar às suas partes a mesma destinação que tem a edificação, e não as utilizar de maneira prejudicial ao sossego, salubridade e segurança dos possuidores, ou aos bons costumes por fim, o condômino compromete-se a não fugir do uso normal da coisa, ainda que detenha grande fração ideal; este dever vale também para a presença de animais no condomínio.

\section{ADMINISTRAÇÃO: ASSEMBLEIA, SÍNDICO E CONSELHO}

A administração do condomínio é exercida pelo síndico, cujo mandato não pode exceder dois anos, permitida a reeleição (art. 1.347 do CC). Importante ressaltar, o condomínio não tem personalidade jurídica, mas pode figurar em um dos polos da ação. Nesses casos é representado judicialmente pelo síndico, ativa e passivamente, em juízo ou fora dele.

No que tange à assembleia, deve-se ocorrer obrigatoriamente uma Assembleia Geral Ordinária, convocada pelo síndico. Nesta, além das matérias escritas na pauta do dia, podem

\footnotetext{
${ }^{7}$ STJ - REsp 1350721-DF 2012/0222549, Relator: Ministro Ricardo Villas Bôas Cueva, 3ạ Turma, Publicação: DJ 10/04/2015.

${ }^{8}$ Neste sentido: STJ - AREsp 676852-DF 2015/0054903-3, Relator: Ministro Raul Araújo, Publicação: DJ 12/06/2015; TJRJ - APL 000375288.2012.8.19.0087, Relatora: Maria Ferreira Alvarenga, Publicação: DJe 20/03/2014; TJSP - APL 9105791-97.2003.8.26.0000, Relator: James Siano, Publicação: DJe 24/08/2011.

${ }^{9}$ DABUS MALUF, C. A.; MARQUES, M. A. M. R. Condomínio edilício. 3. ed. São Paulo: Saraiva, 2010, p. 68.
} 
aprovar, por maioria dos presentes, orçamento das despesas, contribuição dos condôminos e a prestação de contas (art. 1.350 do CC). Estas decisões, respeitando-se o quórum fixado na convenção, obrigam a todos, inclusive votos vencidos e ausentes.

É possível também a convocação de Assembleia Geral Extraordinária, pelo síndico ou por um quarto dos condôminos, no mínimo, para deliberar sobre interesses gerais (art. 1.355 do CC), sendo possível alterar a convenção do condomínio e o regulamento interno, respeitando-se o quórum de dois terços dos condôminos.

O síndico é a pessoa que representa os condôminos e o condomínio, podendo ser um dos condôminos, pessoa física ou pessoa jurídica estranha ao condomínio. Ainda, na ausência do síndico, pode-se haver um subsíndico (art. 1.348, § 2ํㅡ, do CC).

O síndico é assessorado por um conselho consultivo, composto por três condôminos, com mandato de dois anos, permitida a reeleição. Por fim, o art. 1.356 do CC estabelece o conselho fiscal, com competência para analisar os orçamentos do condomínio.

\section{BENFEITORIAS E DESPESAS}

O art. 1.341 do Código Civil, divide as obras existentes nos Condomínios Edilícios em voluptuárias, úteis e necessárias. As voluptuárias são aquelas de mero deleite ou recreio, tendo somente a finalidade de tornar o bem mais agradável, dependendo da votação de dois terços dos condôminos para sua realização. As úteis são aquelas que aumentam ou facilitam o uso do bem, $\mathrm{e}$ dependem do voto da maioria dos condôminos. Por fim, as necessárias são aquelas que têm a finalidade conservar o bem, e independem de votação em assembleia.

Em se tratando de obras ou reparações necessárias, estas poderão ser realizadas, independentemente de autorização, pelo síndico ou, no caso de omissão ou impedimento deste, por qualquer integrante do condomínio - o condômino que realizar as obras de caráter necessário será restituído das efetivas despesas. No mais, não são permitidas construções nas áreas comuns, uma vez que não se pode prejudicar as partes próprias e comuns dos condôminos em geral.

A construção de outro pavimento ou solo comum de outro edifício, para novas unidades imobiliárias, depende da unanimidade dos condôminos. Há aqui uma grande crítica pela doutrina - o condomínio ser ou não pessoa jurídica. A grande corrente aduz que o condomínio edilício não tem esse caráter e isso dificulta, quando não torna impraticável, em alguns casos, a conseguir adquirir novas unidades para o condomínio, pois existem inúmeros imóveis que possuem centenas de condôminos, impossibilitando a rubrica de todos no documento ${ }^{10}$.

\section{EXTINÇÃO DO CONDOMÍNIO EDILÍCIO}

As áreas comuns integrantes do condomínio edilício não podem ser divididas, haja vista tratar-se de áreas coletivas pertencentes aos condôminos, sem distinção de partes. Assim, segundo os ensinamentos de Gonçalves (2015, p. 433):

Diferentemente do condomínio tradicional, que pode ser extinto, a todo tempo, pela divisão ou venda da coisa comum, o condomínio edilício, que incide sobre o solo e partes e coisas comuns do edifício e sobre a propriedade exclusiva das unidades, tem como característica essencial a indivisibilidade, sendo constituído para perpetuar-se no tempo. Desse

\footnotetext{
${ }^{10}$ A nova lei civil perdeu a oportunidade de dar personalidade jurídica ao condomínio, tão necessária a esse instituto, que dela precisa para poder interagir com maior desenvoltura no mundo jurídico, principalmente no que tange à aquisição de bens imóveis que se possam incorporar ao prédio já existente. Como caso concreto podemos apontar, por exemplo, a impossibilidade da compra, em nome do condomínio, de terreno contíguo para ampliar as vagas de garagem, pela falta de personalidade jurídica, obrigando os próprios condôminos, se quiserem, a adquirir em seu nome a propriedade, o que muitas vezes inviabiliza o negócio (MONTEIRO, W. de B.; DABUS MALUF, C. A., 2013, p. 292).
} 
modo, não pode ser extinto pelos condôminos, por convenção ou por via judicial, pois a indivisibilidade é da própria essência do instituto.

Conforme a legislação poderá ser extinta das seguintes formas: a) destruição do prédio por fatores alheios à vontade dos condôminos (art. 1.357, caput, primeira parte, do CC) - são, v. g., os casos de incêndio ou inundação; b) demolição voluntária do prédio (art. 1.357, caput, in fine, do CC) - esta ocorrerá em casos de ruína, podendo-se deliberar pela reconstrução ou venda do que restar; c) desapropriação do imóvel (art. 1.358 do CC) - se a demolição for total, o valor do condomínio será repartido de acordo com a fração pertencente a cada integrante e as áreas comuns serão repartidas de formas iguais. Se parcial, somente os proprietários lesados serão indenizados pelo prejuízo ${ }^{11}$; d) por fim, o condomínio será extinto se ocorrer a confusão, ou seja, se todas as frações forem obtidas por um só sujeito ${ }^{12}$.

\section{CONCLUSÃO}

Foi possível observar, o condomínio edilício está presente na sociedade desde os tempos mais anosos, e que ganha cada vez mais espaço ultimamente.

Poder-se-ia falar na aplicação do Código Civil como norma principal ao condomínio edilício, por possuir normas precisas e recentes, usando-se sua lei especial em caso de omissão do mesmo, vez que se trata de interpretação mais benéfica. No caso de permissão de animais, como visto, o Superior Tribunal de Justiça deu sua última palavra, sendo totalmente possível, atendidos os cuidados mínimos, já que tudo deve ser sopesado, mormente em face dos princípios constitucionais.

Ainda, em aglomerados de pessoas ou residências são comuns a presença de divergências e dúvidas acerca de direitos, o que é comum do ser humano, não sendo admissível a não atribuição de personalidade jurídica ao condomínio. Ao menos, o Poder Judiciário pode ser acionado a qualquer tempo para resolução de situações assim, dada sua inafastabilidade.

Conclui-se, o condomínio edilício é um integrante com espaço garantido no direito de propriedade, com infinita importância, merecendo total valorização, sobretudo pela veloz modernização das cidades, acréscimo demográfico e precário espaço urbano atual.

\section{REFERÊNCIAS}

BRASIL. Código Civil. 4. ed. In: Curia; Céspedes; Nicoletti. Vade Mecum. São Paulo: Saraiva, 2014.

BRASIL. Congresso Nacional. Condomínio em Edificações. Lei n. 4.591 de 16 de dezembro de 1964. Dispõe sobre o condomínio em edificações e as incorporações imobiliárias. Diário Oficial da União, Brasília, DF, 21 dez. 1964. Disponível em: <http:// www.planalto.gov.br/ccivil_03/leis/L4591.htm>. Acesso em: 27 jun. 2017.

BRASIL. Constituição (1988). Constituição da República Federativa do Brasil. Brasília: Senado Federal, 1988.

BRASIL. Lei de Introdução às Normas do Direito Brasileiro. 4. ed. In: Curia; Céspedes; Nicoletti. Vade Mecum. São Paulo: Saraiva, 2014.

COELHO, Fábio Ulhoa. Curso de direito civil: direito das coisas, direito autoral. v. 4. 6. ed. São Paulo: Saraiva, 2015.

\footnotetext{
${ }^{11}$ Pode ocorrer, também, mais remotamente, a desapropriação de uma única ou algumas unidades autônomas. Neste caso a indenização competirá somente aos proprietários das unidades expropriadas. (GONÇALVES, 2015, p. 434)

${ }^{12}$ Podemos ainda considerar causa de extinção do condomínio a confusão, que ocorre quando todas as unidades autônomas forem adquiridas por uma só pessoa (DABUS MALUF, C. A.; MARQUES, M. A. M. R., 2010, p. 157).

Colloquium Socialis, Presidente Prudente, v. 01, n. Especial 2, Jul/Dez, 2017, p.326-332. DOI: 10.5747/cs.2017.v01.nesp2.s0156
} 
DABUS MALUF, C. A.; MARQUES, M. A. M. R. Condomínio edilício. 3. ed. São Paulo: Saraiva, 2010.

DINIZ, Maria Helena. Código Civil anotado. 15. ed. São Paulo: Saraiva, 2010.

GONÇALVES, Carlos Roberto. Direito civil brasileiro: direito das coisas, v. 5. 10. ed. São Paulo: Saraiva, 2015.

MONTEIRO, W. de B.; DABUS MALUF, C. A. Curso de direto civil: direito das coisas. v. 3. 43. ed. São Paulo: Saraiva, 2013.

ORIGEM DA PALAVRA - SITE DE ETIMOLOGIA. Disponível em: <http://origemdapalavra.com.br/site/ palavras/condominio/>. Acesso em: 26 jun. 2017.

RODRIGUES, Silvio. Direito Civil: direito das coisas. v. 5. 28. ed. São Paulo: Saraiva, 2009.

TARTUCE, Flávio. Manual de direito civil. v. ú. 6. ed. São Paulo: Forense, 2016.

VENOSA, Sílvio de Salvo. Direito civil: direitos reais. v. 5. 13. ed. São Paulo: Atlas, 2013. 